\title{
Current Evidence on Coronavirus Disease-2019: A Comprehensive Review
}

\author{
Mangla Sood ${ }^{1}$, Seema Sharma ${ }^{2}$
}

\begin{abstract}
Coronavirus disease-2019 (COVID-19) pandemic has become an unprecedented public health challenge for clinicians and policymakers across the globe. COVID-19, the infectious disease caused by the novel coronavirus severe acute respiratory syndrome-associated coronavirus-2 (SARS(oV-2), has been shown to affect all ages, particularly, the aged and elderly, and has reached massive proportions globally. We aim to review the current clinical epidemiology, pathophysiology, clinical presentations, and treatment for this rapidly growing novel disease globally, and discuss infection prevention, control, and management strategies put forth by World Health Organization (WHO), Centers for Disease Control and Prevention (CDC), the Ministry of Health and Family Welfare (MoHFW) to the Govt of India, and Indian Council of Medical Research (ICMR) for this huge public health concern. Reviewing the current evidence for COVID-19 is imperative to help understand effective preventive and treatment measures for this novel threat to humanity.
\end{abstract}

Keywords: COVID-19, Pandemic, Severe acute respiratory syndrome-associated coronavirus-2.

Pediatric Infectious Disease (2021): 10.5005/jp-journals-10081-1286

\section{INTRODUCTION}

A mammoth global pandemic due to coronavirus disease-2019 (COVID-19) has emerged as a novel threat to humanity. As of November 27, 2020, it has affected more than 61 million cases in a span of 11 months. ${ }^{1}$ Case fatality rates (CFRs) for the previous epidemic causing coronaviruses were far lower. For SARS-CoV-1, it was estimated at $10 \%$ and for MERS-CoV at $35 \%$ with about 800 deaths in each epidemic ${ }^{2}$ but severe acute respiratory syndrome-associated coronavirus-2 (SARS-CoV-2) has caused more than 1,442,668 deaths worldwide and is still raging on. Knowledge regarding COVID-19 is evolving and a review of the latest evidence is essential to understand the appropriate management of SARS-CoV-2. This review discusses updates of the public health threat due to COVID-19 including pathophysiology, transmission, diagnosis, and treatment guidelines developed by the leading health agencies of the world.

\section{Materials and Methods}

This review was synthesized after collecting and analyzing data from World Health Organization (WHO) COVID-19 statistics and guidelines, Centers for Disease Control and Prevention (CDC) COVID-19 recommendations, and the Ministry of Health and Family Welfare (MoHFW) and Indian Council of Medical Research (ICMR) COVID-19 statistics. We also conducted an extensive literature search of databases including PubMed, LitCovid, and unpublished work in MedRxiv using the search terms "coronavirus", "severe acute respiratory syndrome coronavirus 2", "2019-nCoV", "SARS-CoV-2", "SARS-CoV", "MERS-CoV", and "COVID-19" for studies published from January 1, 2020, to November 20, 2020, citing relevant articles, prioritizing randomized clinical trials, systematic reviews, and clinical practice guidelines.

\section{Observations}

\section{Etiology and Pathophysiology}

COVID-19 disease is caused by the novel coronavirus SARS-CoV-2, a single-stranded RNA (ribonucleic acid) virus, with distinctive spikes
${ }^{1}$ Department of Pediatrics, Indira Gandhi Medical College, Shimla, Himachal Pradesh, India

${ }^{2}$ Department of Pediatrics, Dr Rajendra Prasad Government Medical College, Kangra, Himachal Pradesh, India

Corresponding Author: Mangla Sood, Department of Pediatrics, Indira Gandhi Medical College, Shimla, Himachal Pradesh, India, Phone: +91 9418453465, e-mail: drmanglasood@gmail.com

How to cite this article: Sood M, Sharma S. A Current Evidence on Coronavirus Disease-2019: A Comprehensive Review. Pediatr Inf Dis 2021;3(2):65-73.

Source of support: Nil

Conflict of interest: None

that give it a "crown-like" appearance. Severe acute respiratory syndrome-associated coronavirus- 2 is thought to be a virus of animal origin, originating in bats, with subsequent rapid human to human transmission via an intermediate host. ${ }^{3}$ Compared to the previous epidemic causing coronaviruses SARS-CoV-1 (2002-2003) and MERS-CoV (2012), SARS-CoV-2 is far more contagious with greater sustainability and spread, probably due to mutations causing increased affinity to the host cell receptor needed for cell entry. COVID-19 has emerged as a multisystem disease; viral spike (S) protein targets angiotensin-converting enzyme 2 (ACE2) receptor found in multi-organ including the heart, endothelium, kidney, gastrointestinal tract, liver, and endocrine system. ${ }^{4}$

Among adult patients, the commonest complications due to COVID-19 are the cytokine storm and pneumonia with acute respiratory distress syndrome (ARDS), resulting from mononuclear inflammatory infiltrates in interstitial spaces and edema with hyaline membrane formation that appears as ground-glass opacities on chest computed tomography (CT) imaging. Features differentiating COVID-19 ARDS from other causes of ARDS include thrombosis in the pulmonary microvasculature, good tolerance to hypoxia in initial stages (happy hypoxia/silent hypoxia), and good lung compliance initially, followed by a rapid decline in lung function. ${ }^{4,5}$

(0) The Author(s). 2021 Open Access This article is distributed under the terms of the Creative Commons Attribution 4.0 International License (https:// creativecommons.org/licenses/by-nc/4.0/), which permits unrestricted use, distribution, and non-commercial reproduction in any medium, provided you give appropriate credit to the original author(s) and the source, provide a link to the Creative Commons license, and indicate if changes were made. The Creative Commons Public Domain Dedication waiver (http://creativecommons.org/publicdomain/zero/1.0/) applies to the data made available in this article, unless otherwise stated. 
COVID-19 has also been shown to cause a prothrombotic state and consumption of clotting factors resulting from fulminant disruption of the epithelial-endothelial barrier integrity, and arterial and venous thromboembolism. Cardiovascular complications include myocarditis, heart failure, arrhythmias, and myocardial infarction; neurologic complications include strokes, encephalopathy, and seizures, endocrine complications like adrenocortical insufficiency, hyperglycemia, and ketosis. Other complications like acute kidney, liver dysfunction, and hemophagocytic lymphohistiocytosis (HLH) have been described. ${ }^{5}$

\section{Viral Transmission}

Severe acute respiratory syndrome-associated coronavirus-2 is spread by respiratory droplets generated during coughing, sneezing, and talking. Face to face contact (within 6 feet for $>15$ minutes), or staying in the same room for $>2$ hours increases transmission risk. The highest risk is for household contacts with secondary attack rates ranging between 30 and $50 \%$. It is believed that as much as $48-62 \%$ of transmission of COVID-19 occurs from pre-symptomatic/asymptomatic individuals as these people may not realize that they are sick and do not follow infection control precautions. ${ }^{6}$ Although microdroplets could remain viable in the air for up to 3 hours and prolonged periods on surfaces, transmission from inanimate surfaces contaminated with the virus is assumed to be less important than thought earlier. ${ }^{7}$ Though the virus is excreted in stool, the risk of fecal-oral transmission is uncertain. Maternal COVID-19 is currently believed to be associated with a low risk for vertical transmission during intrauterine, intrapartum, and breastfeeding. ${ }^{8}$

The virus is highly contagious and though early estimates during the initial outbreak in China indicated a basic reproductive number (R0) of 2.2-2.7, which is greater than seasonal influenza (R0 of 1), the R0 number is thought to be even greater at 5.7 for SARSCoV-2 infection. Viral shedding starts 2-3 days before the onset of symptoms and peaks at the onset of symptoms. Viral cultures are generally negative for SARS-CoV-2 8 days after symptom onset, even though viral nucleic acid can be detectable in throat swabs for up to 6 weeks after the onset of illness. ${ }^{9}$

\section{Testing and Diagnosis}

Reverse transcriptase-polymerase chain reaction (RT-PCR) based testing of upper respiratory tract swabs (nasopharyngeal and oropharyngeal) for SARS-CoV-2 nucleic acid has been recommended as the gold standard for COVID-19. ${ }^{10}$ The result is expressed as the cycle threshold [Ct] (cutoff is $40-45$ for a positive test). A high $\mathrm{Ct}$ indicates a low viral load and vice versa. The correlation of disease severity and $\mathrm{Ct}$ value is not yet established. Compared to samples from bronchoalveolar lavage and sputum having a sensitivity of 95 and 70\%; nasopharyngeal, oropharyngeal, and nasal swabs have low sensitivity of 50,30 , and $20 \%$, respectively. ${ }^{11}$

Recently, antigen-based testing for the diagnosis of COVID-19 has been recommended for testing in the containment zones and hospitals. ${ }^{10}$ While it is the point of care, highly specific, and has a turnaround time of only 15 minutes, it has a very low sensitivity of only $20 \%$. So, while a positive antigen test unequivocally confirms COVID-19, a negative test does not exclude it and needs confirmation by RT-PCR.

Serology-based tests that detect humoral immune response to current or past infection are also available for the diagnosis of SARSCoV-2 infection. IgM antibodies are seen within 5 days of infection while IgG antibodies are detectable around 14 days after symptom onset. These tests are only recommended for retrospective diagnosis in patients with a high clinical suspicion for COVID-19 who had previously tested negative by RT-PCR or were not tested at all, for diagnosis of pediatric multisystem inflammatory syndrome, for seroprevalence studies, and for determining antibody content of convalescent plasma. $^{12}$

\section{COVID-19: Clinical Manifestations}

The incubation period is 2-14 days and most studied cohorts have a male:female ratio of 60:40 with the median age of hospitalized patients between 47 years and 73 years. ${ }^{13}$ The clinical symptoms include fever (70-90\%), respiratory symptoms like dry cough $(60-86 \%)$, shortness of breath $(53-80 \%)$, rhinorrhea $(7 \%)$, fatigue (38\%), myalgia/myositis (15-44\%), weakness (25\%), headache, encephalopathy, gastrointestinal symptoms like nausea/vomiting, diarrhea (15-39\%), coagulopathy, renal and liver dysfunction. ${ }^{13-15}$ Dermatological manifestations like maculopapular rashes, urticaria, vesicles, petechiae, purpura, chilblains, livedo racemosa, and distal limb ischemia are seen among $5-20 \%$ of patients. ${ }^{16}$ Anosmia or ageusia may be the sole presenting symptom in approximately $3 \%$ of patients with COVID-19. ${ }^{17}$

\section{COVID-19 in Children}

Children are affected less severely with COVID-19, most having mild disease. This may be due to better innate immunity, adaptive immunity due to exposure to other viruses, recent administration of vaccines including Bacille Calmette Guerin (BCG) and Measles, Mumps and Rubella (MMR), healthier lungs, and immature ACE receptors. ${ }^{18}$ Cases of severe COVID-19 pneumonia and adverse outcomes are usually seen in infants and those with comorbidities. Although initially children constituted only $2 \%$ of total cases, the latest reports in the United States indicate a steady increase in cases and now $9.8 \%$ of all positive COVID-19 cases are pediatric, accounting for $4 \%$ of all COVID-19 hospitalizations. ${ }^{19}$ Moreover, recently, a unique entity temporally associated with SARS-CoV-2 is being recognized in children labeled multisystem inflammatory syndrome in children (MIS-C). It tends to manifest about 1 month later after the peak of SARS-CoV-2 infection in affected populations. ${ }^{20}$ Even though it shares clinical and laboratory features of Kawasaki disease (KD) and Kawasaki-shock syndrome or bacterial toxic shock syndrome (TSS), the demographic and inflammatory processes are different from the classical description, with higher cases of COVID-19 children manifesting with coronary artery aneurysms and hypotension as shown in a recent systematic review. ${ }^{21}$ Multisystem inflammatory syndrome in children appears to be due to an aberrant immune response to a previous COVID-19 infection. Children between the ages of 5 years and 15 years are most commonly affected and present with high fever, rash, gastrointestinal symptoms. These children may rapidly progress to shock and show reduced ejection fraction and coronary artery dilatation on echocardiography. The lungs are sparingly involved. Laboratory investigation shows neutrophilia, normal or low platelet counts, high C-reactive protein (CRP)/ erythrocyte sedimentation rate (ESR), high interleukin-6 (IL-6), high ferritin, and troponin levels. As many as $60 \%$ of affected children need intensive care, ${ }^{21}$ and treatment with high dose steroids, intravenous immunoglobulin, aspirin, and other immunomodulatory agents like tocilizumab. With appropriate treatment, short-term outcomes are good with rapid improvement in ejection fractions and coronary artery aneurysms. While MIS-C is rare, pediatricians should keep a high index of suspicion for sick children during the COVID-19 pandemic presenting with fever and rash. 


\section{COVID-19 in Pregnant Women and Newborns}

Asymptomatic COVID-19 positive women have outcomes similar to their nonpregnant counterparts. However, women symptomatic for COVID-19 with lower respiratory tract involvement tend to be at higher risk for maternal morbidity and preterm deliveries. All newborns born to COVID-19 positive mothers should be tested for infection as soon as possible after birth. ${ }^{19}$ Intrauterine, intrapartum, and breastfeeding-related transmission including post-natal through close contacts is rare. Furthermore, most infected neonates are asymptomatic or have a mild illness. Therefore, most authorities including the WHO and Indian Academy of Pediatrics recommend that unless symptomatic, the babies should be roomed in with the mothers and breastfeeding continued with the mother wearing a mask and practicing good hand hygiene. ${ }^{8}$ Routine vaccines including BCG, oral polio vaccine (OPV), and hepatitis $B$ should be given before discharge.

\section{Predictors of Serious COVID-19 Disease and Mortality}

Studies have shown that about $80 \%$ of patients have mild to moderate illness but 20\% have severe disease manifestations and $5 \%$ become critically ill with complications like ARDS, respiratory failure, septic shock, and multi-organ dysfunction syndrome (MODS). ${ }^{22}$ A recent study reported an admission rate of $17.1 \%$ among all individuals hospitalized with COVID-19 to highdependency or intensive care units (ICUs) ${ }^{23}$ and need mechanical ventilation. The overall CFR is $3 \% .{ }^{24}$ However, several factors affect the determination of CFR like the degree of testing (widespread testing will lead to a decrease in CFR), population demographics (countries with the older population having higher CFR), and access to health and critical care. Risk factors for developing severe disease include chronic medical conditions like diabetes, hypertension, cancer, immunocompromised status, chronic kidney disease, and cardiovascular conditions, as well as, advanced age, obesity, and male gender. ${ }^{25}$ Poor prognostic laboratory parameters include $\mathrm{SpO}_{2}<90 \%$, D-dimer $>1,000 \mathrm{ng} / \mathrm{mL}$, elevated CRP, creatine phosphokinase (CPK), and lactate dehydrogenase (LDH) levels, raised troponin and ferritin levels, absolute lymphocyte count $<1,000 / \mu \mathrm{L}$, neutrophil-lymphocyte ratio $>3.5$, and IL-6 levels $>7$ to 10 times of normal [30]. Extensive involvement on the chest CT scan also indicates worse outcomes. ${ }^{25}$

\section{Management Strategies for COVID-19}

COVID-19 infected patients are classified into different categories based upon symptoms. Table 1 describes the suggested management protocol of these patients. Very mild/presymptomatic/asymptomatic COVID-19 patients without clinical evidence of lower respiratory tract involvement, are to be treated at home provided (i) facilities for isolation are available, (ii) there is reliable access to medical care, (iii) there are no major comorbidities or compromised immune status (HIV, transplant recipients, cancer therapy, etc.). ${ }^{19,26}$ Patients should be asked to monitor their temperature with a thermometer and oxygen saturation by a pulse oximeter after a 6-minute walk and seek medical attention in case of breathlessness or drop in saturation. For patients with moderate and severe COVID-19 disease, awake proning has been proven to be beneficial in improving oxygenation and is strongly recommended. ${ }^{27}$ Patients with refractory hypoxemia should be put on high flow nasal oxygen (HFNO) and these patients may need endotracheal intubation and mechanical ventilation. Extracorporeal membrane oxygenation (ECMO) has been practiced in resourcerich settings, and there are anecdotal reports of successful lung transplants in patients with COVID-19.

The following classes of drugs are being developed/ evaluated for the management of COVID-19: antivirals (remdesivir, favipiravir), antibodies (e.g., convalescent plasma, hyperimmune immunoglobulins), anti-inflammatory agents (dexamethasone), targeted immunomodulatory therapies (tocilizumab, sarilumab, anakinra, ruxolitinib), anticoagulants (heparin), and antifibrotics (tyrosine kinase inhibitors). ${ }^{21,28-34}$ Different treatment modalities might likely have different efficacies at different stages of illness. For instance, viral inhibition would be expected to be most effective early in infection, while, in hospitalized patients, immunomodulatory

Table 1: Proposed recommendation for management of COVID-19

\begin{tabular}{|c|c|c|c|c|}
\hline Category & Symptoms & Disease severity & Investigations & Treatment \\
\hline Mild & $\begin{array}{l}\text { The patient has a fever, } \\
\text { cough, sore throat, ma- } \\
\text { laise, myalgia, loss of smell } \\
\text { and taste, GIT symptoms. } \\
\mathrm{SpO}_{2}>94 \% \text { in room air. RR } \\
<24 / \text { minute }\end{array}$ & $\begin{array}{l}\text { Not hospitalized } \\
\text { Or if hospitalized, not on } \\
\text { oxygen }\end{array}$ & $\begin{array}{l}\text { Labs and CT chest are not routinely } \\
\text { indicated }\end{array}$ & $\begin{array}{l}\text { Home-based symptomatic } \\
\text { treatment for fever, nose block, } \\
\text { and cough. Vitamins C, D, and } \\
\text { zinc may be added (unproven } \\
\text { benefit, but may be prescribed } \\
\text { for their placebo value) } \\
\text { No antiviral } \\
\text { No immunomodulator drug }\end{array}$ \\
\hline Moderate & $\begin{array}{l}\text { The patient has clinical or } \\
\text { radiographic evidence of } \\
\text { lower respiratory tract in- } \\
\text { fection with } \mathrm{SpO}_{2} 90-94 \% \\
\text { in room air at sea level. RR } \\
24-30 / \text { minute }\end{array}$ & $\begin{array}{l}\text { Hospitalized, on supple- } \\
\text { ment oxygen but not on } \\
\text { high flow nasal cannula, } \\
\text { noninvasive ventilation, or } \\
\text { invasive ventilation }\end{array}$ & $\begin{array}{l}\text { CBC, CRP, LFT, RFT, HbA1C, ECG, } \\
\text { chest X-ray } \\
\text { Depending upon availability can do } \\
\text { (procalcitonin, CPK, LDH, D-dimer, } \\
\text { ferritin, troponin I, CT chest with or } \\
\text { without pulmonary angiography } \\
\text { and screening 2D echocardiogram, } \\
\text { blood cultures) }\end{array}$ & $\begin{array}{l}\text { Close monitoring, maintain hy- } \\
\text { dration, start empirical antibiot- } \\
\text { ics, which can be de-escalated if } \\
\text { no evidence of bacterial sepsis } \\
\text { Antiviral drugs and/or dexa- } \\
\text { methasone may be used. The } \\
\text { role of convalescent plasma is } \\
\text { questionable }\end{array}$ \\
\hline Severe & $\begin{array}{l}\text { Patients with } \mathrm{SpO}_{2}<90 \% \\
\text { on room air at sea level. RR } \\
>30 / \text { minute }\end{array}$ & $\begin{array}{l}\text { Hospitalized and on high } \\
\text { flow nasal cannula or non- } \\
\text { invasive ventilation }\end{array}$ & $\begin{array}{l}\text { CBC, CRP, LFT, RFT, HbA1c, ECG, } \\
\text { chest X-ray }\end{array}$ & $\begin{array}{l}\text { Close monitoring, maintain hy- } \\
\text { dration, start empirical antibiot- } \\
\text { ics, which can be de-escalated if } \\
\text { no evidence of sepsis }\end{array}$ \\
\hline
\end{tabular}


Contd...

\begin{tabular}{|c|c|c|c|c|}
\hline Category & Symptoms & Disease severity & Investigations & Treatment \\
\hline & $\begin{array}{l}\mathrm{PaO}_{2}: \mathrm{FiO}_{2}<300 \mathrm{~mm} \mathrm{Hg} \text {, } \\
\text { lung infiltrates }>50 \%\end{array}$ & & $\begin{array}{l}\text { Depending upon availability can do } \\
\text { (procalcitonin, CPK, LDH, D-dimer, } \\
\text { ferritin, troponin I, CT chest with or } \\
\text { without pulmonary angiography } \\
\text { and screening 2D echocardiogram, } \\
\text { blood cultures). Monitor for com- } \\
\text { plications including arrhythmias, } \\
\text { myocarditis, acute coronary syn- } \\
\text { drome, venous thromboembolism, } \\
\text { and secondary bacterial and fungal } \\
\text { infections }\end{array}$ & $\begin{array}{l}\text { Lasix, heparin, antiviral drugs, } \\
\text { and dexamethasone may be } \\
\text { used }\end{array}$ \\
\hline Critical & $\begin{array}{l}\text { ARDS, septic shock, car- } \\
\text { diac dysfunction, hepatic, } \\
\text { renal, CNS, or thrombotic } \\
\text { disease. Elevation of } \\
\text { multiple inflammatory cy- } \\
\text { tokines and/or exacerba- } \\
\text { tion of comorbidities }\end{array}$ & $\begin{array}{l}\text { Hospitalized and on inva- } \\
\text { sive ventilation or ECMO }\end{array}$ & $\begin{array}{l}\text { CBC, CRP, LFT, RFT, HbA1c, ECG, } \\
\text { chest X-ray } \\
\text { Depending upon availability can do } \\
\text { (procalcitonin, CPK, LDH, D-dimer, } \\
\text { ferritin, troponin I, CT chest with or } \\
\text { without pulmonary angiography } \\
\text { and screening 2D echocardiogram, } \\
\text { blood cultures). Monitor for com- } \\
\text { plications including arrhythmias, } \\
\text { myocarditis, acute coronary syn- } \\
\text { drome, venous thromboembolism, } \\
\text { and secondary bacterial and fungal } \\
\text { infections }\end{array}$ & $\begin{array}{l}\text { Hemodynamic support, } \\
\text { vasopressors, a trial of awake } \\
\text { prone position to improve } \\
\text { oxygenation. CRRT if AKI. } \\
\text { Dexamethasone**, Lasix**, } \\
\text { heparin***, anticoagulants****, } \\
\text { and antiviral drugs***** may be } \\
\text { used }\end{array}$ \\
\hline
\end{tabular}

CRRT, continuous renal replacement therapy; ECMO, extracorporeal membrane oxygenation

*Dexamethasone: $8 \mathrm{mg}$ or methylprednisolone $40 \mathrm{mg}$ OD for 5-10 days

**Lasix: To maintain a negative balance of 300 to $1,000 \mathrm{~mL}$ volume

***Heparin: 5,000 units SC as OD for prophylaxis, 5,000 to 7,500 units BD therapeutic, or enoxaparin: $1 \mathrm{mg} / \mathrm{kg}$ OD prophylaxis, BD therapeutic

****Anticoagulant as aspirin: $150 \mathrm{mg}$ OD or aspirin $75 \mathrm{mg}$ + dabigatran $75 \mathrm{mg} \mathrm{BD} \mathrm{for} \mathrm{6-12} \mathrm{weeks} \mathrm{post-discharge}$

*****Antivirals: remedesivir, favipiravir

agents may be useful to prevent disease progression. The different classes of medications, their mechanisms of action, dosages, adverse effects, and current indications in COVID-19 management are shown in Table 2. Low molecular weight heparin (LMWH) is indicated in all patients with severe disease to prevent thrombotic complications. Broad-spectrum antibiotics should be given only if bacterial coinfection is suspected. Alternative approaches being studied include the use of convalescent plasma-derived hyperimmune globulin and monoclonal antibodies targeting SARSCoV-2. ${ }^{35}$ Blood group and SARS-CoV-2 antibodies should be tested if administration of convalescent plasma is planned.

\section{Prognosis}

There is a variation of mortality rates across cohorts, reflecting differences in the completeness of testing and case identification, variable thresholds for hospitalization, and differences in outcomes. Among patients admitted to ICUs, mortality is around $30 \%$, which is increased to $75-80 \%$ among patients on mechanical ventilation. ${ }^{36}$ Hospital mortality ranges from $<5 \%$ among patients younger than 40 years to $35 \%$ for patients aged $70-79$ years and $>60 \%$ for patients aged $>80$ years. ${ }^{19}$ The actual numbers of deaths from COVID-19 are difficult to ascertain because not all people who die during the pandemic are tested for COVID-19. Survival from sepsis is associated with increased risk for mortality for at least 2 years with increased vulnerability to recurrent infection and further health deterioration. ${ }^{37}$

There are reports of lingering signs and symptoms among patients who had recovered from acute COVID-19, called long COVID-19. ${ }^{38}$ Some of the reported persistent symptoms include fatigue, joint pain, chest pain, palpitations, shortness of breath, and worsened quality of life, impaired pulmonary function even 1 month after hospital discharge. Patients continue to experience neurologic and psychiatric symptoms, high rates of anxiety and depression, headaches, vision changes, hearing loss, loss of taste or smell, impaired mobility, numbness in extremities, tremors, myalgia, memory loss, cognitive impairment, and mood changes for up to 3 months after diagnosis of COVID-19. Readmissions in patients recovered from severe COVID are not uncommon and are usually related to bacterial/other viral infections, changes of lung fibrosis, and thrombotic events. ${ }^{39}$ More research is needed to better understand the pathophysiology and clinical course, and management strategies of these post-infection sequelae. There is evidence of some degree of immunity against re-infection from SARS-CoV-2 as seen in previous studies on SARS-CoV- 1 and studies in rhesus monkeys. However, the duration of immunity and whether it is long-lasting is not well stablished. ${ }^{40}$

\section{Precautions/Prevention and Vaccination}

COVID-19 is a potentially preventable disease, by practicing social distancing, universal masking, and hand hygiene. In general, the preventive interventions can be divided into those consisting of personal actions (physical distancing, personal hygiene, and use of protective equipment), case and contact identification (test tracetrack-isolate), regulatory actions (limits on the size of gatherings; stay-at-home orders; proactive school, workplace, and public transport closure or restriction; cordon sanitaire or internal border closures), and international border measures (e.g., border closure or enforced quarantine). A key priority is to identify the combination of measures that minimizes societal and economic disruption while adequately controlling the infection. 


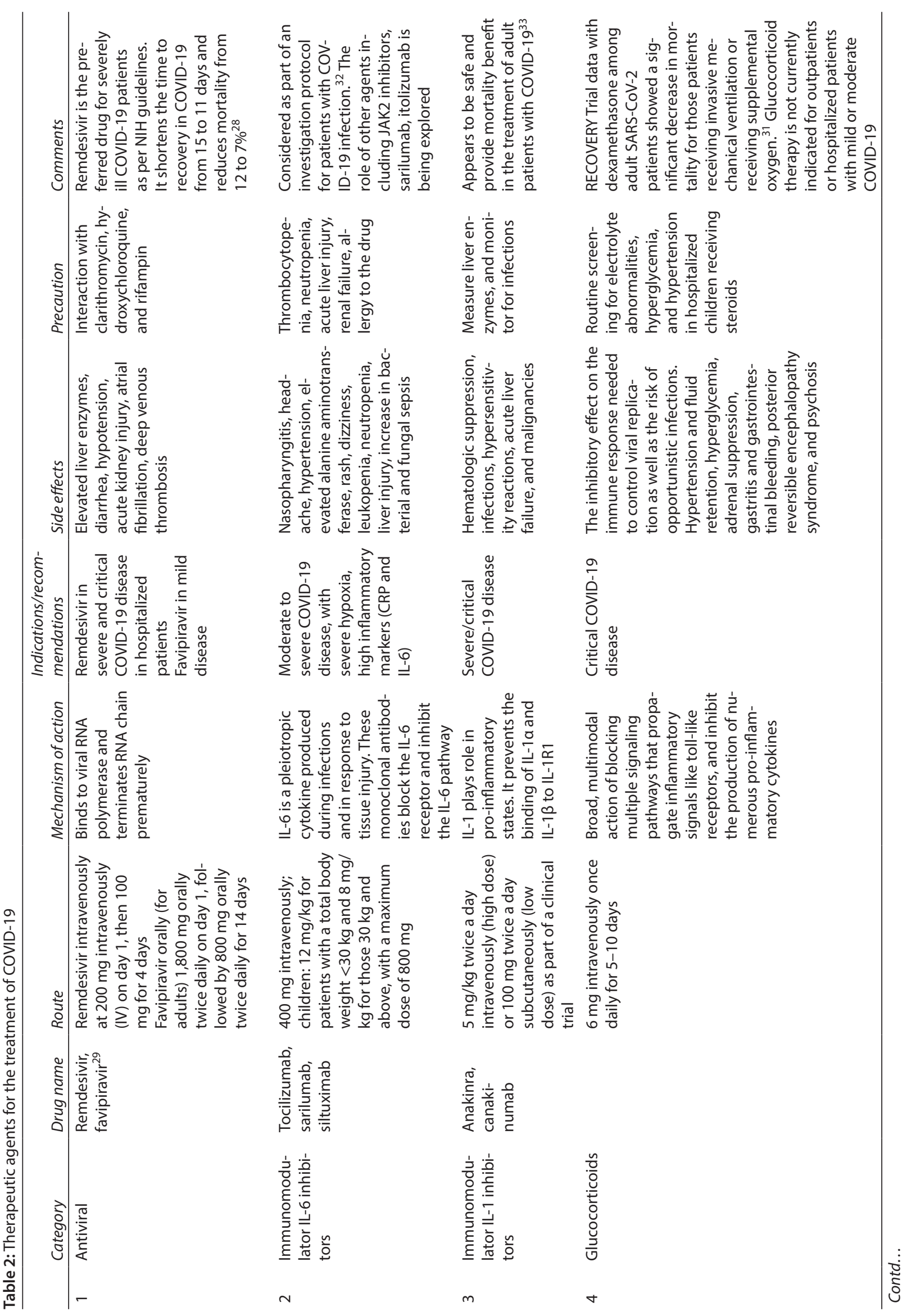




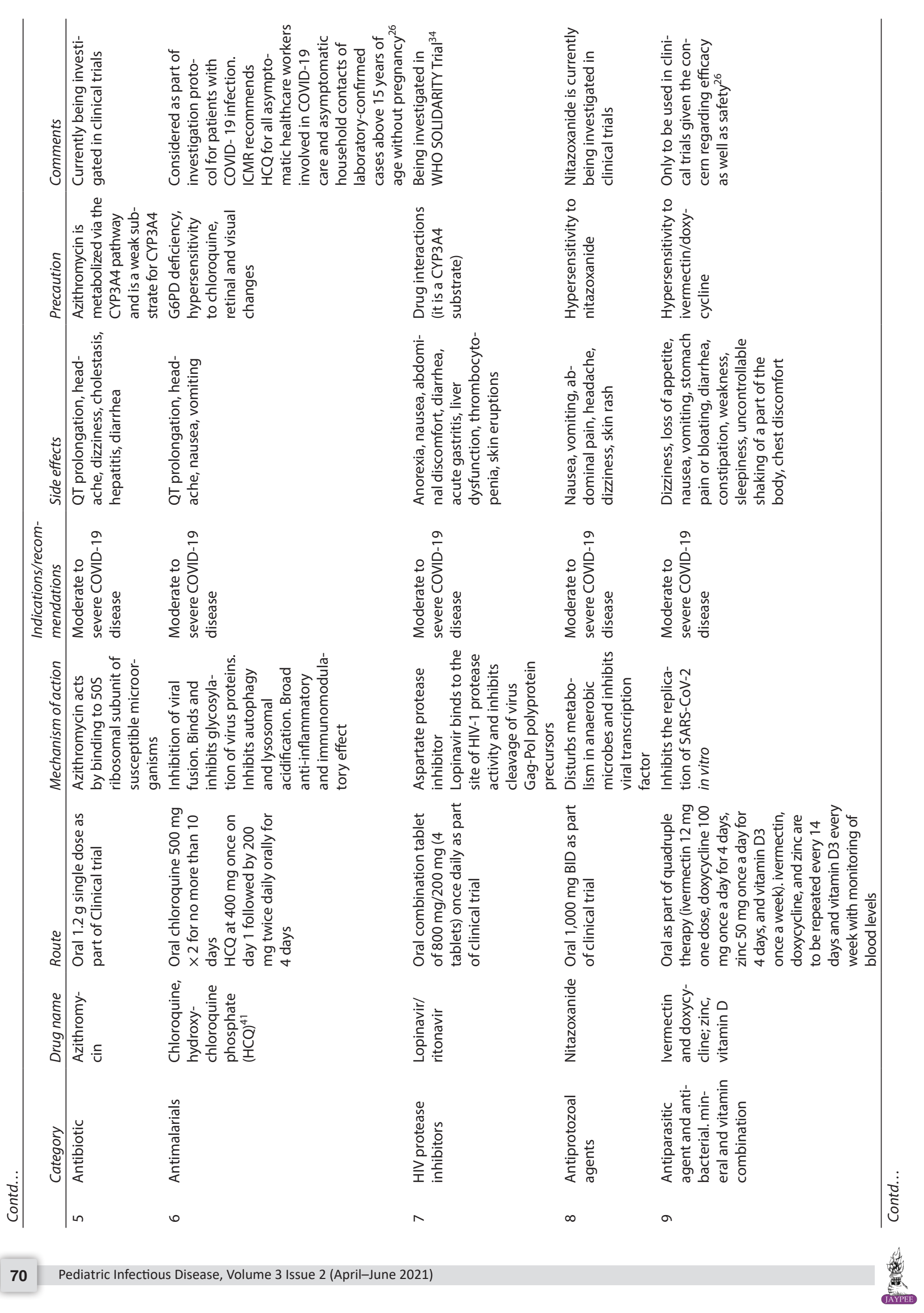




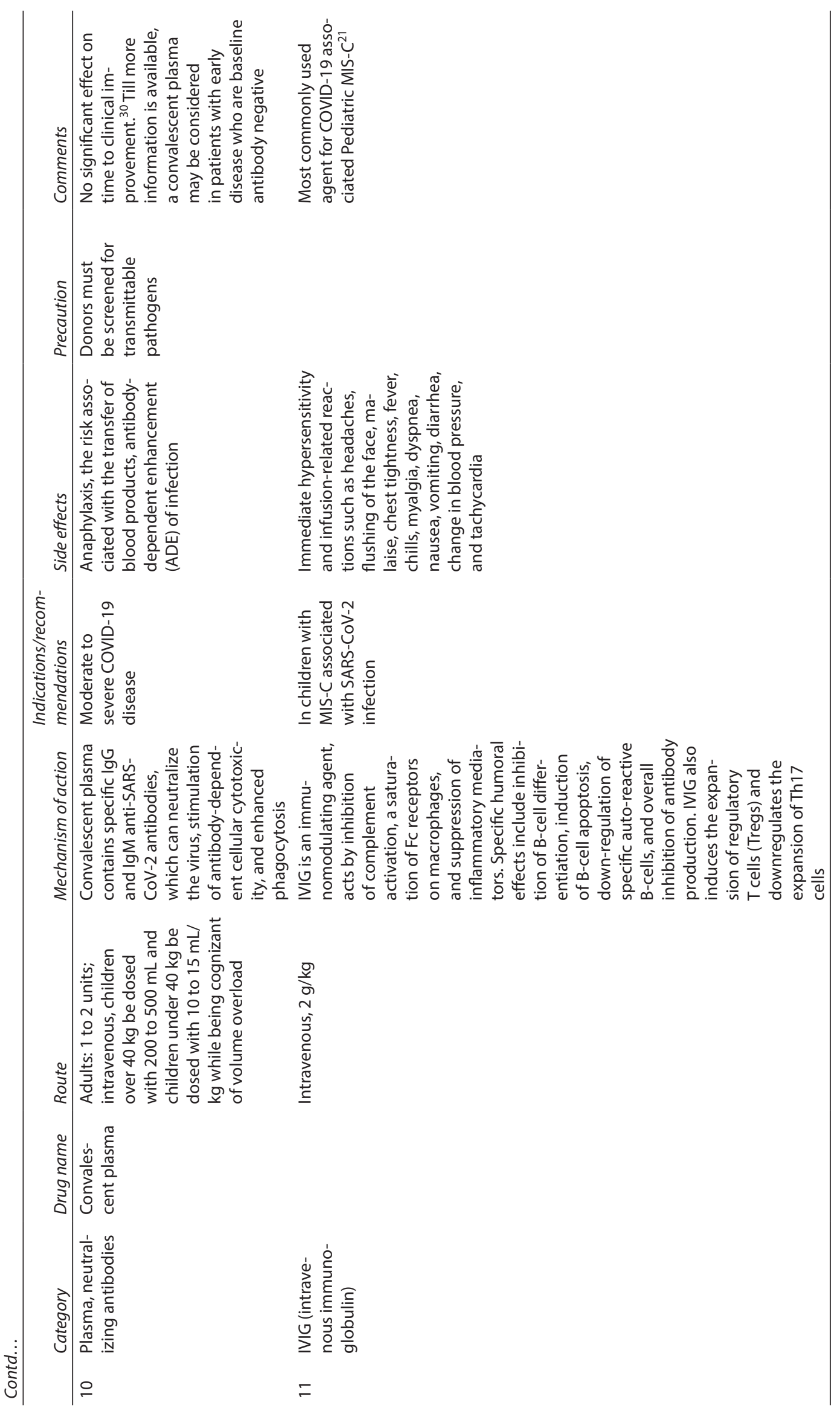


Precautions in hospitals and health care facilities involve appropriate triaging of patients presenting to hospitals, routine screening for COVID-19 before/at the time of admission and procedures, admission of a suspect and confirmed cases to isolation areas, health care worker $(\mathrm{HCW})$ to wear appropriate personal protective equipment $\mathrm{PPE}^{19,26}$ and practice good hand hygiene. Special care should be taken during aerosol-generating procedures such as suctioning, intubation, and tracheostomy. Patients and their relatives in non-COVID areas should be monitored for the development of COVID-like symptoms and tested when necessary. Telemedicine should be encouraged, spacing out appointments, keep face to face appointments short, limit the entry of relatives and walk-in patients, ensure masking, and ensure regular decontamination of OPD areas.

The role of BCG and MMR vaccines in boosting immunity and protecting from COVID-19 has not been established. Similarly, post-exposure prophylaxis with hydroxychloroquine was not found useful in a recent randomized controlled trial. ${ }^{41}$ Pre-exposure prophylaxis with hydroxychloroquine while recommended for health care workers in India since the beginning of the epidemic has not been supported by robust trial data.

There are about 201 vaccine candidates in trials across the world. ${ }^{42}$ Of these, the frontrunners are Moderna Pharmaceuticals mRNA-1273 vaccine, University of Oxford and Astra Zeneca's AZD 1222 vaccine, and Pfizer and BioNTech's BNT 162 vaccine. Apart from these, vaccines from Russia and China are also going through phase 3 trials. Several countries (UK, USA, Bahrain, Saudi Arabia, Canada, Mexico, and Israel) have allowed emergency use authorization of COVID vaccines from Moderna and Pfizer BioNTech as two doses schedule separated over 3-4 weeks for public use. China is also giving an indigenously developed vaccine to its citizens. While the preliminary immunogenicity and safety data appears promising, recently concerns have been raised regarding the safety of some of the vaccines in clinical trials and the most important question is whether the vaccines will be clinically efficacious. Other approaches to prevention are likely to emerge in the coming months, including monoclonal antibodies, and hyperimmune globulin.

\section{Limitations}

This review delineates and provides comprehensive information on current evidence for COVID-19 for clinical practice. Its limitations include information provided here is based on current evidence but may be modified as more information becomes available. Also, very few randomized trials have been published to guide the management of COVID-19.

\section{Conclusion}

In addition to the direct effect on morbidity and mortality, COVID19 has had unprecedented collateral damaging effects in terms of psychological impact, economic suffering, and decreased attention to other life-threatening conditions. United efforts from the government, society, and health care sector are the need of the hour to fight this epidemic, which entails health practitioners keeping updated about new advancements in the field, following guidelines, and the political will and society cooperating with health care professionals in all capacities.

\section{Authors' Contributions}

All authors contributed to the study conception and design. Material preparation, data collection, and analysis were performed by
Mangla Sood and Seema Sharma. The first draft of the manuscript was written by Mangla Sood and Seema Sharma jointly. All authors commented on previous versions of the manuscript. All authors have read and approved the final manuscript, after contributing to the concept, design, definition of intellectual content, literature search, manuscript preparation, manuscript editing, and manuscript review.

\section{Compliance with Ethical Standards}

None of the authors have any financial disclosures or other conflicting relationships. The authors fully acknowledge and comply with the Journal's Conflict of Interest policy. The manuscript has been read and approved by all the authors, that the requirements for authorship as stated earlier in this document have been met, and that each author believes that the manuscript represents honest work.

\section{References}

1. WHO Coronavirus Disease (COVID-19) Dashboard /WHO Coronavirus Disease (COVID-19) Dashboard. Accessed November 26, 2020. https:// covid19.who.int/.

2. Cascella M, Rajnik M, Cuomo A, et al. Features, Evaluation and Treatment Coronavirus (COVID-19). StatPearls Publishing; 2020. Accessed October 30, 2020 http://www.ncbi.nlm.nih.gov/ pubmed/32150360.

3. Lam TT-Y, Jia N, Zhang Y-W, et al. Identifying SARS-CoV-2-related coronaviruses in Malayan Pangolins. Nature 2020;583(7815):282-285. DOI: 10.1038/s41586-020-2169-0.

4. Xu Z, Shi L, Wang Y, et al. Pathological findings of COVID-19 associated with acute respiratory distress syndrome. Lancet Respir Med 2020;8(4):420-422. DOI: 10.1016/S2213-2600(20)30076-X.

5. Li H, Liu L, Zhang D, et al. SARS-CoV-2 and viral sepsis: observations and hypotheses. Lancet 2020;395(10235):1517-1520. DOI: 10.1016/ S0140-6736(20)30920-X.

6. Wei WE, Li Z, Chiew CJ, et al. Presymptomatic transmission of SARSCoV-2-Singapore, January 23-March 16, 2020. MMWR Morb Mortal Wkly Rep 2020;69(14):411-415. DOI: 10.15585/mmwr.mm6914e1.

7. Chin AWH, Chu JTS, Perera MRA, et al. Stability of SARS-CoV-2 in different environmental conditions. Lancet Microbe 2020;1(1):e10. DOI: 10.1016/S2666-5247(20)30003-3.

8. Chawla D, Chirla D, Dalwai S, et al. Perinatal-neonatal management of COVID-19 infection - guidelines of the Federation of Obstetric and Gynaecological Societies of India (FOGSI), National Neonatology Forum of India (NNF), and Indian Academy of Pediatrics (IAP). Indian Pediatr 2020;57(6):536-548. DOI: 10.1007/s13312-020-1852-4. http:// www.ncbi.nlm.nih.gov/pubmed/32238615.

9. Sun J, Xiao J, Sun R, et al. Prolonged persistence of SARS-CoV-2 RNA in body fluids. Emerg Infect Dis 2020;26(8):1834-1838. DOI: 10.3201/ eid2608.201097.

10. Laboratory testing strategy recommendations for COVID-19: interim guidance. Accessed October 30, 2020. https://www.who.int/ publications/i/item/laboratory-testing-strategy-recommendationsfor-covid-19-interim-guidance.

11. Wang W, Xu Y, Gao R, et al. Detection of SARS-CoV-2 in different types of clinical specimens. JAMA 2020;323(18):1843-1844. DOI: 10.1001/ jama.2020.3786.

12. Zhao J, Yuan $\mathrm{Q}$, Wang $\mathrm{H}$, et al. Antibody responses to SARS-CoV-2 in patients with novel coronavirus disease 2019. Clin Infect Dis 2020;71(16):2027-2034. DOI: 10.1093/cid/ciaa344.

13. Garg S, Kim L, Whitaker M, et al. Hospitalization rates and characteristics of patients hospitalized with laboratory-confirmed coronavirus disease 2019-COVID-NET, 14 states, March 1-30, 2020. MMWR Morb Mortal Wkly Rep 2020;69(15):458-464. DOI: 10.15585/ mmwr.mm6915e3. 
14. Zarifian $A$, Zamiri Bidary $M$, Arekhi S, et al. Gastrointestinal and hepatic abnormalities in patients with confirmed COVID-19: a systematic review and meta-analysis. J Med Virol 2020(1):jmv.26314. DOI: 10.1002/jmv.26314.

15. Helms J, Kremer S, Merdji H, et al. Neurologic features in severe SARSCoV-2 infection. N Engl J Med 2020;382(23):2268-2270. DOI: 10.1056/ NEJMc2008597.

16. Marraha F, Al Faker I, Gallouj S. A review of the dermatological manifestations of coronavirus disease 2019 (COVID-19). Dermatol Res Pract 2020;2020:1-9. DOI: 10.1155/2020/9360476.

17. Spinato G, Fabbris C, Polesel J, et al. Alterations in smell or taste in mildly symptomatic outpatients with SARS-CoV-2 infection. JAMA 2020;323(20):2089. DOI: 10.1001/jama.2020.6771.

18. Dhochak N, Singhal T, Kabra SK, et al. Pathophysiology of COVID-19: Why children fare better than adults? Indian J Pediatr 2020;87(7):537546. DOI: 10.1007/s12098-020-03322-y.

19. Coronavirus Disease 2019 (COVID-19) | CDC. Accessed October 30, 2020. https://www.cdc.gov/coronavirus/2019-ncov/index.html.

20. World Health Organization. Multisystem Inflammatory Syndrome in Children and Adolescents Temporally Related to COVID-19.; 2020. Accessed November 9, 2020. https://www.who.int/news-room/ commentaries/detail/multisystem-inflammatory-syndrome-inchildren-and-adolescents-with-covid-19.

21. Kaushik A, Gupta S, Sood M, et al. A systematic review of multisystem inflammatory syndrome in children associated with SARS-CoV-2 infection. Pediatr Infect Dis J 2020;39(11):e340-e346. DOI: 10.1097/ INF.0000000000002888.

22. Guan W, Ni Z, Hu Y, et al. Clinical characteristics of coronavirus disease 2019 in China. N Engl J Med 2020;382(18):1708-1720. DOI: 10.1056/ NEJMoa2002032.

23. Docherty AB, Harrison EM, Green CA, et al. Features of 20133 UK patients in hospital with covid-19 using the ISARIC WHO clinical characterisation protocol: prospective observational cohort study. BMJ 2020;369:m1985. DOI: 10.1136/bmj.m1985.

24. Home-Johns Hopkins Coronavirus Resource Center. Accessed October 30, 2020. https://coronavirus.jhu.edu/.

25. Xu L, Mao Y, Chen G. Risk factors for 2019 novel coronavirus disease (COVID-19) patients progressing to critical illness: a systematic review and meta-analysis. Aging 2020;12(12):12410-12421. DOI: 10.18632/ aging.103383.

26. Government of India. MoHFW_Home. Minist Heal Fam Welfare, Govt India. Published online 2020. Accessed October 30, 2020 https://www. mohfw.gov.in/.

27. Alhazzani W, Møller MH, Arabi YM, et al. Surviving sepsis campaign: guidelines on the management of critically ill adults with coronavirus disease 2019 (COVID-19). Crit Care Med 2020;48(6):e440-e469. DOI: 10.1097/CCM.0000000000004363.

28. Beigel JH, Tomashek KM, Dodd LE, et al. For the treatment of Covid19-final report. N Engl J Med 2020(19):NEJMoa2007764. DOI: 10.1056/NEJMoa2007764.
29. Covid patients given favipiravir showed " $40 \%$ faster" recovery, Glenmark trial results claim. Accessed October 30, 2020. https:// theprint.in/health/covid-patients-given-favipiravir-showed-40faster-recovery-glenmark-trial-results-claim/466327/.

30. Chen $\mathrm{L}$, Xiong J, Bao $\mathrm{L}$, et al. Convalescent plasma as a potential therapy for COVID-19. Lancet Infect Dis 2020;20(4):398-400. DOI: 10.1016/S1473-3099(20)30141-9.

31. RECOVERY Collaborative Group. Dexamethasone in hospitalized patients with Covid-19_preliminary report. N Engl J Med 2020. NEJMoa2021436. DOI: 10.1056/NEJMoa2021436.

32. Patel K, Gooley TA, Bailey N, et al. Use of the IL-6R antagonist tocilizumab in hospitalized COVID-19 patients. J Intern Med 2020. joim.13163. DOI: 10.1111/joim.13163.

33. Monteagudo LA, Boothby A, Gertner E. Continuous intravenous anakinra infusion to calm the cytokine storm in macrophage activation syndrome. ACR Open Rheumatol 2020;2(5):276-282. DOI: 10.1002/acr2.11135.

34. "Solidarity" clinical trial for COVID-19 treatments. Accessed Ocyober 31, 2020. https://www.who.int/emergencies/diseases/novelcoronavirus-2019/global-research-on-novel-coronavirus-2019-ncov/ solidarity-clinical-trial-for-covid-19-treatments.

35. Brouwer PJM, Caniels TG, van der Straten $\mathrm{K}$, et al. Potent neutralizing antibodies from COVID-19 patients define multiple targets of vulnerability. Science 2020;369(6504):643-650. DOI: 10.1126/science. abc5902.

36. Potere N, Valeriani E, Candeloro M, et al. Acute complications and mortality in hospitalized patients with coronavirus disease 2019: a systematic review and meta-analysis. Crit Care 2020;24(1):389. DOI: 10.1186/s13054-020-03022-1.

37. Prescott $\mathrm{HC}$, Angus $\mathrm{DC}$. Enhancing recovery from sepsis. JAMA 2018;319(1):62. DOI: 10.1001/jama.2017.17687.

38. Tenforde MW, Kim SS, Lindsell CJ, et al. Symptom duration and risk factors for delayed return to usual health among outpatients with COVID-19 in a multistate health care systems network-United states, March-June 2020. MMWR Morb Mortal Wkly Rep 2020;69(30):993998. DOI: $10.15585 / \mathrm{mmwr} . \mathrm{mm} 6930 \mathrm{e}$.

39. Rokadiya S, Gil E, Stubbs C, et al. COVID-19: outcomes of patients with confirmed COVID-19 re-admitted to hospital. J Infect 2020;81(3):e18e19. DOI: 10.1016/j.jinf.2020.07.007.

40. Phelan AL. COVID-19 immunity passports and vaccination certificates: scientific, equitable, and legal challenges. Lancet 2020;395(10237):1595-1598. DOI: 10.1016/S0140-6736(20) 31034-5.

41. Boulware DR, Pullen MF, Bangdiwala AS, et al. A randomized trial of hydroxychloroquine as postexposure prophylaxis for Covid-19. N Engl J Med 2020;383(6):517-525. DOI: 10.1056/NEJMoa2016638.

42. World Health Organization. Draft landscape of COVID-19 candidate vaccines - 15 May 2020. Who. 2020; (March):3. Accessed August 27, 2020. https://www.who.int/who-documents-detail/draft-landscapeof-covid-19-candidate-vaccines. 